\title{
Retraction
}

\section{Retracted: The Effect of Elephantopus scaber L. on Liver Regeneration after Partial Hepatectomy}

\author{
Evidence-Based Complementary and Alternative Medicine \\ Received 8 August 2017; Accepted 8 August 2017; Published 26 November 2017 \\ Copyright (C) 2017 Evidence-Based Complementary and Alternative Medicine. This is an open access article distributed under the \\ Creative Commons Attribution License, which permits unrestricted use, distribution, and reproduction in any medium, provided \\ the original work is properly cited.
}

Evidence-Based Complementary and Alternative Medicine has retracted the article titled "The Effect of Elephantopus scaber L. on Liver Regeneration after Partial Hepatectomy" [1]. The article was found to contain images with the following concerns: The tubulin bands in Figures 2(a) and 2(c) are the same; in Figure 3(a), in the top row there is a vertical line, the first row has a uniform background in the first six lanes, the second row is highly similar to the third row though with increased contrast and the height reduced, and the tubulin and HGF lanes do not align; in Figure 3(b), the top row has no background noise in the first three lanes, the background has irregularities in the fifth lane from the right, and the tubulin lanes do not align with the rest; in Figure $3(\mathrm{c})$, the fourth row has irregularities in the background in the first six lanes, and the tubulin lanes do not align with the rest; in Figure 5(a), the top row has a horizontal line across the band, there are two vertical lines in the tubulin row between the first and second lanes and between the fourth and fifth lanes. The authors provided corrected figures, which are available as Supplementary Materials, but could not provide the underlying blots.

\section{References}

[1] C.-C. Tsai, J.-P. Wu, Y.-M. Lin et al., "The effect of Elephantopus scaber $L$. on liver regeneration after partial hepatectomy," Evidence-Based Complementary and Alternative Medicine, vol. 2013, Article ID 369180, 11 pages, 2013. 


\title{
The Effect of Elephantopus scaber L. on Liver Regeneration after
} Partial Hepatectomy

\author{
Chin-Chuan Tsai, ${ }^{1,2}$ Jia-Ping Wu, ${ }^{3}$ Yueh-Min Lin, ${ }^{4,5}$ Yu-Lan Yeh, \\ Tsung-Jung Ho, ${ }^{6}$ Chia-Hua Kuo, ${ }^{7}$ Bor-Show Tzang, ${ }^{8,9}$ Fuu-Jen Tsai, ${ }^{10}$ \\ Chang-Hai Tsai, ${ }^{11}$ and Chih-Yang Huang ${ }^{3,10,12}$ \\ ${ }^{1}$ School of Chinese Medicine for Post-Baccalaureate, I-Shou University, No 91. Hsueh-Shih Road, Taichung, R.O.C., \\ Kaohsiung 40402, Taiwan \\ ${ }^{2}$ Chinese Medicine Department, E-Da Hospital, Kaohsiung, Taiwan \\ ${ }^{3}$ Graduate Institute of Basic Medical Science, China Medical University, Taichung 40402, Taiwan \\ ${ }^{4}$ Department of Pathology, Changhua Christian Hospital, Changhua, Taiwan \\ ${ }^{5}$ Department of Medical Technology, Jen-Teh Junior College of Medicine, Nursing and Management, Miaoli, Taiwan \\ ${ }^{6}$ Chinese Medicine Department, China Medical University Beigang Hospital, Taiwan \\ ${ }^{7}$ Laboratory of Exercise Biochemistry, Taipei Physical Education College, Taipei, Taiwan \\ ${ }^{8}$ Department of Biochemistry, School of Medicine, Chung Shan Medical University, Taichung, Taiwan \\ ${ }^{9}$ Clinical Laboratory, Chung Shan Medical University Hospital, Taichung, Taiwan \\ ${ }^{10}$ Graduate Institute of Chinese Medical Science, China Medical University, Taichung, Taiwan \\ ${ }^{11}$ Department of Healthcare Administration, Asia University, Taichung 40402, Taiwan \\ ${ }^{12}$ Department of Health and Nutrition Biotechnology, Asia University, Taichung 40402, Taiwan
}

Correspondence should be addressed to Chih-Yang Huang; cyhuang@mail.cmu.edu.tw

Received 15 June 2012; Revised 4 December 2012; Accepted 4 December 2012

Academic Editor: R. Govindarajan

Copyright (C) 2013 Chin-Chuan Tsai et al. This is an open access article distributed under the Creative Commons Attribution License, which permits unrestricted use, distribution, and reproduction in any medium, provided the original work is properly cited.

Liver regeneration after partial hepatectomy $(\mathrm{PHx})$ is a physiological response for maintaining homeostasis. The aim of this study is to investigate effects of Elephantopus scaber L.- (ESL-) induced liver regeneration on growth factors (HGF and IGF-1), cell cycle regulation, and apoptosis suppressed. In this study, we fed five Chinese medicinal herbs ( $1 \mathrm{~g} / \mathrm{kg} / \mathrm{day})$, Codonopsis pilosula (CP, Dangshen), Salvia miltiorrhiza Bunge (SMB, Danshen,), Bupleurum kasi (BK, Chaihu), Elephantopus scaber L. (ESL, TengKhia-U), and Silymarin (Sm, $25 \mathrm{mg} / \mathrm{kg}$ ) for 7 days to male Spraue-Dawley rats. Then surgical 2/3 PHx was conducted and liver regeneration mechanisms were estimated on the following $24 \mathrm{hrs}$ and $72 \mathrm{hrs}$. The activities of growth factors (HGF and IGF-I) and cell cycle proteins were measured by Western blot and RT-PCR. Histological analysis and apoptosis were detected by H\&E stain and TUNEL. The results showed that extraction of Elephantopus scaber L. (ESL) and Silymarin (Sm, positive control) were increased protein expression levels of HGF and IGF-1 which leads into cell cycle. These results suggest that the ESL plays a crucial role in cell cycle-induced liver regeneration and apoptosis. These results suggested that the ESL plays a crucial role in cell cycle-induced liver regeneration and suppressed hepatocytes apoptosis.

\section{Introduction}

The liver is an excellent tissue when it is underwent surgical resection for growth regulation. Hepatocytes are ability to regenerate by a process of compensatory growth and then return to quiescent state [1-3]. Much of the investigation on the mechanisms of hepatic growth has been done in partial hepatectomy ( $\mathrm{PHx})$. Most liver cancer patients have to section partial liver by surgery. After surgery, hepatocytes need to regeneration and increase cell numbers. The native hepatocyte function cannot maintain the integrated whole liver function. Therefore, we suggested that Chinese herbal 
medicines may act as cell cycle progression agents. On the other hand, Silymarin has been used to protect the liver agent as a cytoprotection for treatment of liver disease. Several mechanisms of cytoprotection have been identified, but liver resection has not been reported. In vitro and animal studies have suggested that milk thistle's active ingredient, Silymarin, promoted hepatocyte regeneration and survival [4]. In this study, we suggested Silymarin as a positive control. Almost immediately after PHx, there are major changes in the complete mitogens expression for hepatocytes and in the expression of a relatively large number of genes. TGF betal is a potent antagonist to the mitogenic effects of terminating the proliferative response of hepatocytes during liver regeneration [5-7].

In this study, we detected traditional Chinese medicines, such as Codonopsis pilosula (CP), Salvia miltiorrhiza Bunge (SMB), Bupleurum kasi (BK), Elephantopus scaber L. (ESL), and Silymarin $(\mathrm{Sm})$ effects on liver regeneration. Codonopsis pilosula is an widely edible traditional Chinese medicine (TCM) in China [8]. Some paper studies evaluate that CP would be even stimulated the survival signaling [9], control cell cycle [10], and antiscar formation. Salvia miltorrhiza Bunge root is also a traditional Chinese medicine, which is considered to promote blood flow and remove blood stasis. Some studies show that SMB has protective effects on human kidney possibly through inhibition of inflammatory cytokines and has long been used for treating liver and heart disease in China $[11,12]$. Recent papers have indicated that SMB plays an adjuvant role in inhibited the proliferation and anticarcinogenesis. Bupleurum kasi is one of the most important traditional Chinese crude drug $[13,14]$ for treating hepatitis malaria and intermittent fever. It has the function of soothing the liver. BK was observed in resisting the level of cytokines and antifibrosis [15]. Elephantopus scaber L. is a folk medicine of Taiwan derived from the entire plants of Elephantopus scaber L. E mollis H.B.K and Pseudeelephantopus spicatus (Jass) Rohr. However, some studies elucidated Taiwan folk as a medicine. ESL has hepatoprotective effects [16]. There are some studies showed that ESL exerted anticancer effects on various cancer cells and induced cancer cells apoptosis from cell cycle arrest $[17,18]$.

As it is well known, partial patients with hepatocellular carcinoma need section partial liver. At the same time, liver needs proliferation to maintain original liver mass. We detected possible molecular mechanisms for these traditional Chinese medicines by examining the levels of external and intrinsic signal mechanisms. The liver can precisely regulate its growth and mass after surgical resection of hepatic lobes or hepatocytes loss caused. Hepatocyte replication while enlarged liver mass is corrected by apoptosis. Regeneration requires the cytokines TGF-betal to prevent cytotoxicity. In addition, extensive remodeling of the hepatic extracellular matrix occurs shortly after PHx. Several growth factors have been suggested to play a crucial role in liver regeneration after treatment TCM. HGF is believed to play a primary role in liver regeneration and promotes cell proliferation, survival, and morphogenesis through regulated DNA synthesis. Downstream of hepatocyte growth factor receptor activation is FAK (focal adhesion kinase), an important mediator of integrin signaling in the regulation of cell cycle, survival and regulates cell cycle progression $[19,20]$. However, we also detected cell apoptosis expression by examining the levels of cytochrome $\mathrm{c}$ and bad from mitochondrial to find cell lost.

\section{Materials and Methods}

2.1. Animals. Male Sprague-Dawley rats weighing 180 to 220 $g$ were obtained from the Animal House of National Science Council in Taiwan, and house five to a cage in a room with a controlled temperature of $22 \pm 5^{\circ} \mathrm{C}$, relative humidity of about $60 \%$ and free access to standard food in pellets and tapwater. Two or three cages were randomly assigned into the same group. All rats were acclimatised for 1 week prior to the beginning of all experiments.

2.2. Preparation of Hot-Water Extract from Chinese Medical Herbs. The hot-water extract was prepared by boiling the dried roots with distilled water for $1 \mathrm{~h}$. The extract was filtered, freeze-dried, and kept at $4^{\circ} \mathrm{C}$. The yield of extraction which Codonopsis pilosula (CP, Dangshen)was 21.34\% [21], Salvia miltiorrhizae Bunge (SMB, Danshen) was 16.95\% [22], Buplearum kaoi (BK, Chaihu) was 23.24\% [23], Elephantopus scaber L. (ESL, Teng-Khia-U) was 11.84\% [20], and Silymarin (Sm) was $16.73 \%$ [24]. The dried extract was dissolved in distilled water before use.

2.3. Experimental Partial Hepatectomy (PHx) and Sham $(0 h r)$. Three randomly selected animals were used for each time point. After injecting ketamine subcutaneously at a dose of $30 \mathrm{mg} / \mathrm{kg}$, liver resections consisting of $2 / 3$ of the liver mass were performed in partial hepatectomy group. Animals underwent the same operative anesthesia with the partial hepatectomy (PHx) group [25]. All the surgical operations were done the same as $\mathrm{PHx}$, except the liver lobes were not resected. All the operations were performed between 8:00 AM and 12:00 PM to minimize diurnal effects. After completion of the procedure, the animals were placed under a lamp to prevent hypotermy and then put into cages (five animals per cage) with continuous supply of food and water. The animals in the PHx and corresponding were sacrificed at $6 \mathrm{hrs}, 24 \mathrm{hrs}, 72 \mathrm{hrs}$, and $168 \mathrm{hrs}$ after the operation. The group of animals in which no surgery was performed, was used as control liver group and mentioned time " 0 " in quantitated groups. After all animals were sacrificed by cervical dislocation, the remnant liver lobes were excised and washed in PBS, then immediately frozen in liquid nitrogen.

2.4. Histological Analysis. Rats of all groups from different parts of time at $0 \mathrm{hr}, 6 \mathrm{hrs}, 24 \mathrm{hrs}$, and $72 \mathrm{hrs}$ were sacrificed. The liver sections were taken out and fixed in $10 \%$ formalin and embedded in paraffin. Paraffin blocks were cut into 5-mm sections and stained with Hematoxylin-eosin (H\&E) solution stain [26]. Silymarin (Sm, $25 \mathrm{mg} / \mathrm{kg}$ ) oral gavages after PHx at $0 \mathrm{hr}, 6 \mathrm{hrs}, 24 \mathrm{hrs}$, and $72 \mathrm{hrs}$ were also sacrificed and fixed and stained with H\&E solution stain. 
2.5. Transferase-Mediated dUTP Nick End Labeling (TUNEL). Left ventricular sections were deparaffinized by immersing in xylene, rehydrated, and incubated in $2 \% \mathrm{H}_{2} \mathrm{O}_{2}$ to inactivate endogenous peroxidases. The sections were then incubated with proteinase $\mathrm{K}(20 \mu \mathrm{g} / \mathrm{mL})$, Protein $\mathrm{K}$, working solution: [10-20 ug/ml in $10 \mathrm{mM}$ Tris/HCl, $\mathrm{pH}$ 7.4-8]. Use Proteinase $\mathrm{K}$ from Roche Applied Science, because it is tested for absence of nucleases which might lead to false-positive results $[27,28]$. Wash in phosphate-buffered saline, and incubated with terminal deoxynucleotidyl transferase for $90 \mathrm{~min}$ and fluorescein isothiocyanate-Dutp for $300 \mathrm{~min}$ at $37^{\circ} \mathrm{C}$ using an apoptosis detection kit [29]. Silymarin (S, $25 \mathrm{mg} / \mathrm{kg}$ ) and Elephantopus scaber L. (ESL) oral gavages after PHx at $6 \mathrm{hrs,}$ $24 \mathrm{hrs}$, and $72 \mathrm{hrs}$ were also fixed and stained with kit. Samples were analyzed in a drop of PBS under a fluorescence and UV light microscope at this state by an excitation wavelength in the range of $450-500 \mathrm{~nm}$.

2.6. Western Blot. Proteins were separated by $12 \%$ SDSPAGE and then transferred to nitrocellulose. Membranes were blocked in 5\% milk (diluted in Tris-buffered saline and $0.1 \%$ Tween 20 ) and incubated with the appropriate primary antibodies (TGF $\beta 1$, HGF, IGF-I, Cyclin D1, Cyclin $\mathrm{E}, \mathrm{pRb}$, cytochrome c, Bad, and $\mathrm{E} 2 \mathrm{~F})$ at $4^{\circ} \mathrm{C}$ overnight and HRP anti-IgG was used as secondary reagent. After extensive washing, the targeted proteins were detected by enhanced chemiluminescence (ECL) [30].

2.7. Reverse Transcriptase PCR (RT-PCR). $0.5 \mu \mathrm{g}$ of total RNA derived from liver plus primers by RT-PCR. The firststrand synthesis kit was applied according to the manufacturer's instructions of PCR. The primer pairs used for each gene were as follows.

(1) Cyclin D1: F:5' AGGAGACCATTCCCCTGACT3' R:5' TTCTTCСТCСАСТTССССТT3

(2) pRb: F:5' AGGAGGACTGTTCTCTAAGG3'

R:5' GAGTGAGGTGTGTCTTCTGA3'

(3) E2F: F:5'AACATCCAGAACATCCAGTGGGTAGGCAG3'

R:5' GGCTGTCAGTAGCCTCCAAG3'

(4) Cyclin E:F: 5' CACCCCTGGCATCTTCTCCTT3'

R:5' AGCGTCTTCAGAGACAGCCAG3'

(5) Cytochrome c: F:5' ACAGCACGCTTGTGGAT3'

R:5' GTCTTCAAGCAAGAGGACCA3'

(6) Bad: F:5' TAAGACTCACCTGGGTACTG3

R:5' GCATGTAGTCACTCTTCACC3'
(7) GAPDH: F:5' GGGTGTGAACCACGAGAAAT3

\section{R:5' CCACAGTCTTCTGAGTGGCA3}

The RT-PCR results were analyzed based on the assessment of product sizes upon ethidium bromide agarose gel electrophoresis. For each gene, we determined the cycle number of PCR reactions in which the PCR reaction was not saturated [31]. Based on this, we used the following PCR conditions, The initial denaturation step was at $95^{\circ} \mathrm{C}$, then at annealing temperature and extension at $72^{\circ} \mathrm{C}$. The final extension at $72^{\circ} \mathrm{C}$ for $10 \mathrm{~min}$ was applied to all the reactions and the PCR products were electrophoresed on a $1.2 \%$ agarose gel.

2.8. Quantification of Western Blot and RT-PCR. The intensity (area $\times$ density) of the individual bands on western blots and RT-PCR were measured by densitometry [32]. The background was subtracted from the calculated area.

2.9. Statistical Analysis. All data examined were expressed as mean \pm S.E. For Western blot and RT-PCR analysis, quantitation was carried out by scanning and analyzing the intensity of the hybridization signals using FUJIFILM Imagine program. Statistical analysis of the data was performed using SigmaStat software. Comparison between group was made using one way ANOVA test [32]. A $P$ value of less than 0.05 and 0.01 was considered to be statistically significant.

\section{Results}

3.1. Establishment of Liver Regeneration Animal Model Partial Hepatectomy. During liver regeneration after $2 / 3$ hepatectomy, hepatocytes divide once or twice and return to quiescence. We detected the role of Chinese medicinal herbs in the process of liver regenerating after PHx. We suggest that Chinese herbal medicines may act as cell progression agent to make cell progress. Several mechanisms of cytoprotection have been identified, but the mechanisms of liver resection have not been reported. Surgical resection to remove a tumor together with surrounding liver tissue while preserving enough liver remnant for normal body function. After PHx, we found liver regeneration was started at $24 \mathrm{hrs}$ and increases liver mass (Figure 1(b)), until $72 \mathrm{hrs}$ and $168 \mathrm{hrs}$. However, Liver regeneration (\%) was increased at $24 \mathrm{hrs}$, $72 \mathrm{hrs}$ and $168 \mathrm{hrs}$ PHx (Figures 1(a), 1(b), and 1(c)). More commonly, during liver regeneration the liver is injured and it attempts to repair the injured site referred to as internal scar tissue as quickly as possible. Cytokine, TGF $\beta 1$, increased in the plasma very shortly time kinetics and then decreased, but increased at the long time (Figure 1(f)). TGF $\beta 1$ increased reaching plateau amounts at $72 \mathrm{hrs}$ PHx. Hepatocyte proliferation and apoptosis are coordinately regulated by TGF $\beta 1$. TGF $\beta 1$ protein expression were increased by treatment of SMB, CP, ESL, and Sm at $24 \mathrm{hrs}$ PHx. However, at $72 \mathrm{hrs}$ TGF $\beta 1$ was increased only by CP, ESL, and Sm (Figure 1(d)). Silymarin induced TGF $\beta 1$ decreased at $6 \mathrm{hrs} \mathrm{PHx}\left({ }^{*} P<\right.$ 0.05 versus Sham), but increased at $72 \mathrm{hrs}\left({ }^{* *} P<0.01\right.$ versus Sham; ${ }^{\# \#} P<0.01$ versus $\left.P H x\right)$. Silymarin mitigated 


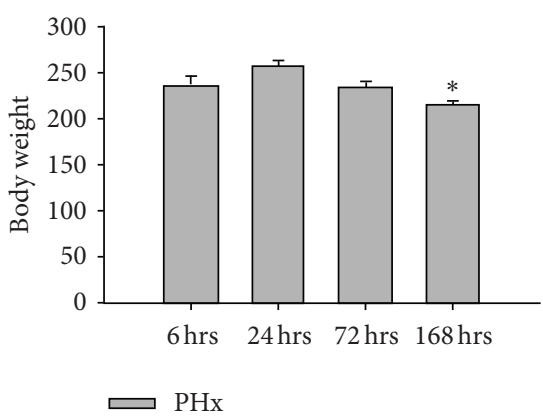

(a)

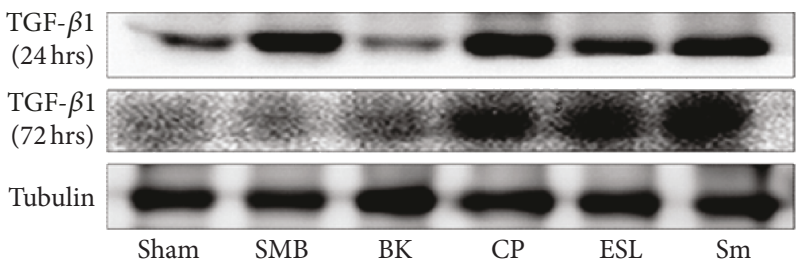

(d)

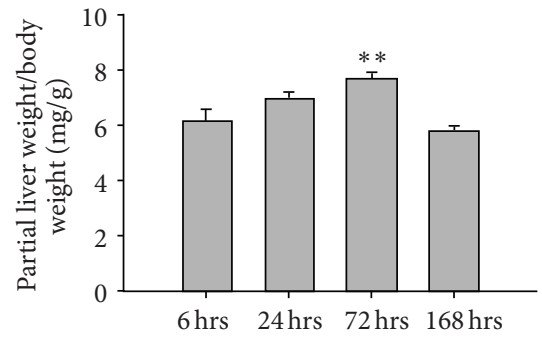

(b)

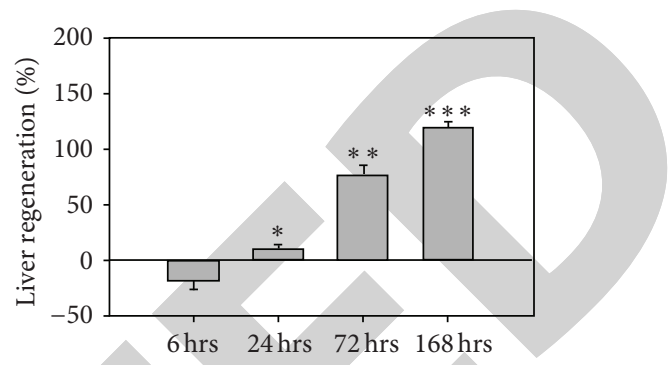

(c)

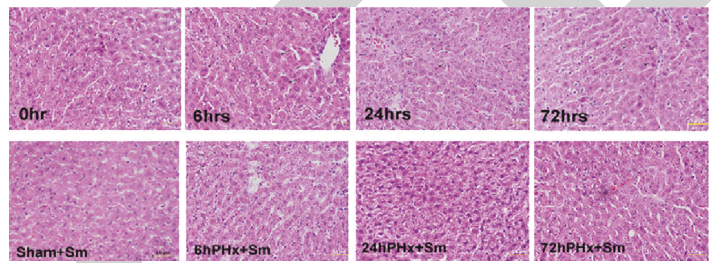

(e)
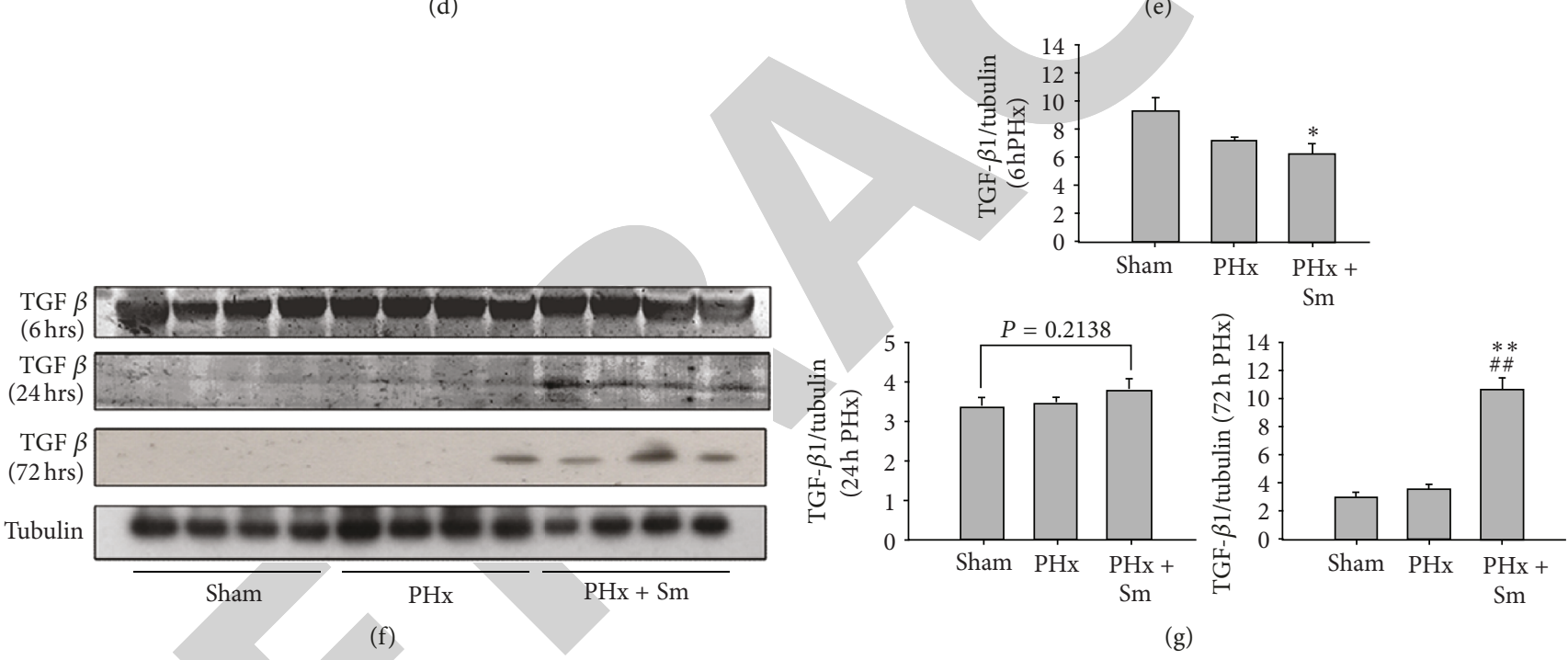

(g)

FIGURE 1: Traditional Chinese medicine improves liver regeneration after liver toxicity injury. (a) Body weight was decreased at $168 \mathrm{hrs}$ PHx. (b) Partial liver weight was increased at $72 \mathrm{hrs} \mathrm{PHx}$. (c) Liver regeneration (\%) was increased at $24 \mathrm{hrs}, 72 \mathrm{hrs}$, and $168 \mathrm{hrs}$ PHx. (d) Cytokines, TGF- $\beta 1$, was increased in SMB, CP, ESL, and Sm at $24 \mathrm{hrs} \mathrm{PHx}$, but CP, ESL, and Sm was at $72 \mathrm{hrs} \mathrm{PHx.} \mathrm{(e)} \mathrm{Histology} \mathrm{of} \mathrm{PHx} \mathrm{section} \mathrm{and}$ after Sm section during liver regeneration. (f) TGF- $\beta 1$ expression was decreased at 6 hrs PHx after Silymarin, but increased at 72 hrs PHx. (g) Quantification of densitometry analysis of protein levels. All data are presented as means \pm SEM, ${ }^{*} P<0.05$ significant difference compared with Sham. ${ }^{\#} P<0.01$ significant difference compared with PHx.

regeneration and made cell normal. At long time, we did not find apoptotic body in regeneration liver (Figure 1(e)).

\subsection{Elephantopus scaber L.-Induced Growth Factors Immedi-} ately Increased after 2/3 PHx. Growth factor signals (HGF and IGF-I) play a role in initiating regeneration of hepatocytes after 2/3 PHx. We suggested that Chinese herbal medicines may act as a cell cycle progression agents to make primed cells progress through the cycle and undergo DNA synthesis. However, progression through the cell cycle beyond the initiation phase requires growth factors. Starting with expression of a large number of immediate growth factors in the regenerating stage, hepatocytes can fully respond to the growth factors (HGF and IGF-I) to stimulate cell cycle from G1 phase to $S$ phase to increase DNA synthesis and rebuild the lost hepatic tissue. ESL and Sm were increased HGF and IGF-I protein expression (Figure 2) $\left({ }^{*} P<0.05\right.$, ${ }^{* *} P<0.01$ versusSham) at $24 \mathrm{hrs}$ PHx and $72 \mathrm{hrs}$ PHx. In addition, Silymarin $(\mathrm{Sm})$ was induced HGF increased compared with Sham or PHx in spite of $6 \mathrm{hrs}, 24 \mathrm{hrs}$, and 72 hrs PHx $\left({ }^{*} P<0.01\right.$ versus Sham; ${ }^{\#} P<0.01$ versus $\left.P H x\right)$ (Figure 3(a)). 


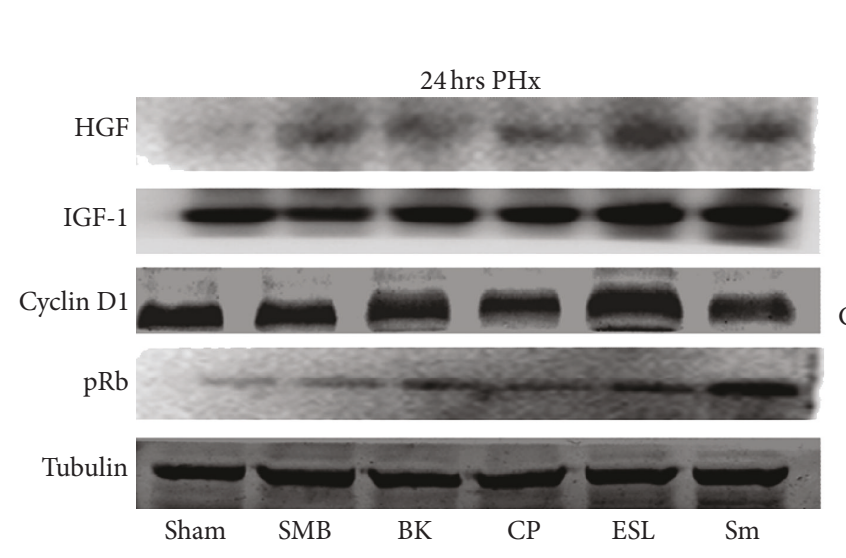

(a)
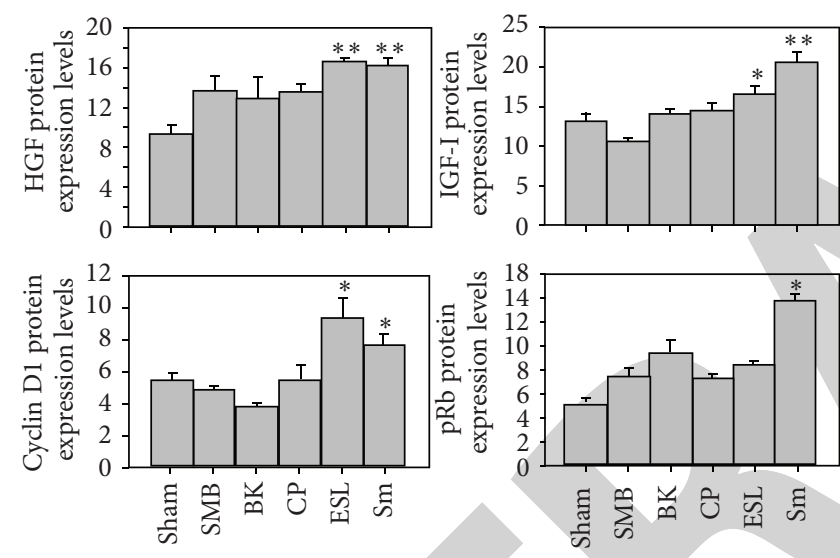

ש $24 \mathrm{hrs}$ PHx

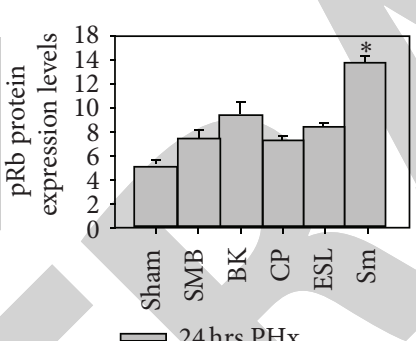

(b)

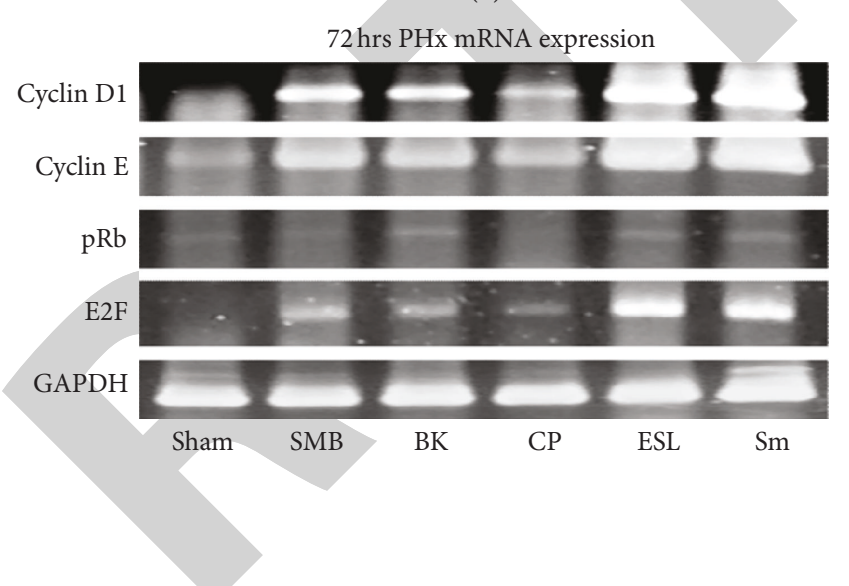

(e)

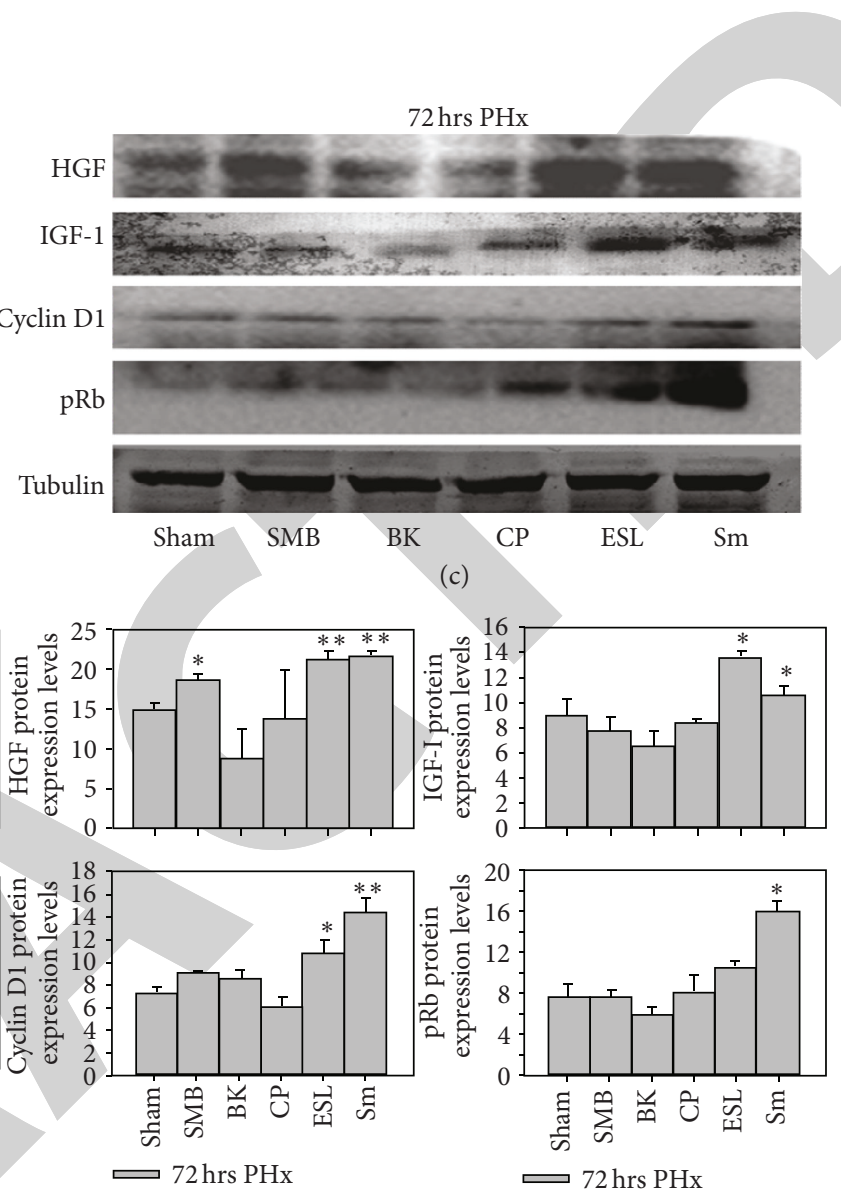

(d)
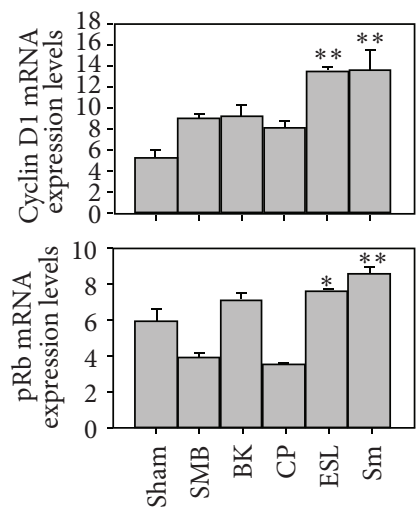

ऍ $72 \mathrm{hrs}$ PHx

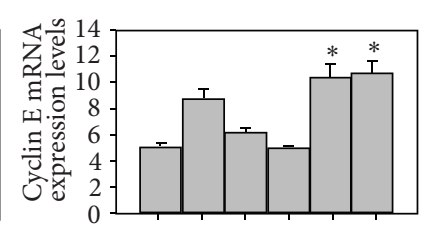

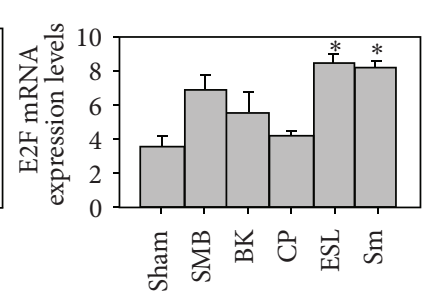

ऍ 72 hrs PHx

(f)

Figure 2: Effects of Elephantopus scaber L. (ESL) and Silymarin (Sm, positive control) on liver regeneration after PHx. (a), (c) Equal amounts of protein lysate were separated by $12 \%$ SDS-PAGE by western blotting with antibodies to HGF, IGF-I, cyclin D1, and pRb. Protein expression levels are increased in Elephantopus scaber L. (ESL) and Silymarin (Sm) at $24 \mathrm{hrs}$ and $72 \mathrm{hrs} \mathrm{PHx} \mathrm{during} \mathrm{liver} \mathrm{regeneration.} \mathrm{(b),} \mathrm{(d).}$ Quantification of densitometry analysis of protein levels. All data are presented as means $\pm \mathrm{SEM},{ }^{*} P<0.05,{ }^{* *} P<0.01$ significant difference compared with Sham group. (e). Expression mRNA of Cyclin D1, Cyclin E, pRb, and E2F were increased in ESL and Sm after 72 hrs PHx. (f). Quantification of densitometry analysis of mRNA levels. All data are presented as means \pm SEM ${ }^{*} P<0.05,{ }^{* *} P<0.01$ significant difference compared with Sham group. 


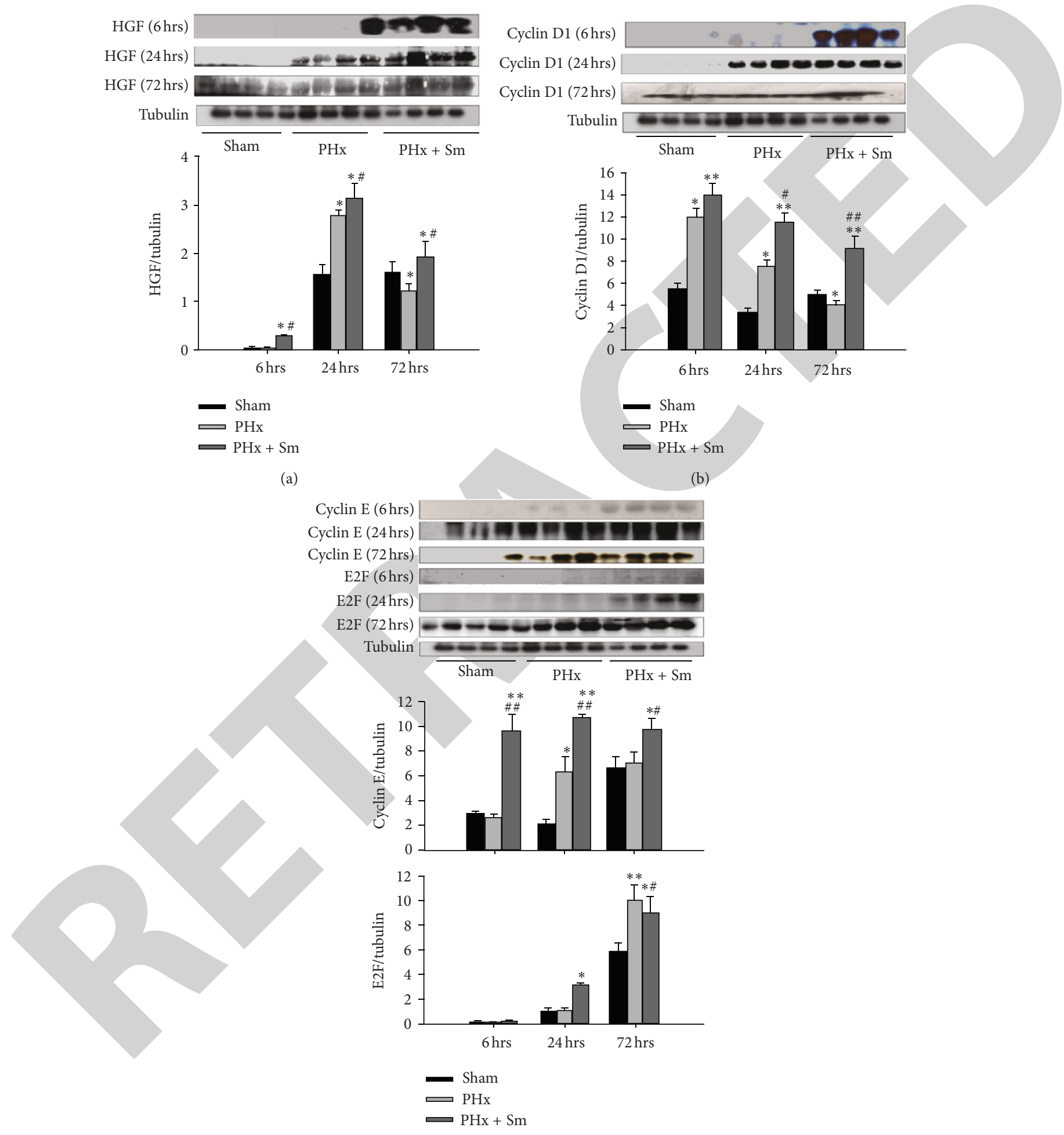

(c)

FIGURE 3: Expression of cell cycle proteins in G1 to S Phase. Western blot analysis of HGF, Cyclin D1, Cyclin E, and E2F expression were increased in Elephantopus scaber L. (ESL) and Silymarin (Sm) at $24 \mathrm{hrs}$ and $72 \mathrm{hrs} \mathrm{PHx.} \mathrm{Tubulin} \mathrm{was} \mathrm{used} \mathrm{as} \mathrm{a} \mathrm{loading} \mathrm{control} \mathrm{for} \mathrm{western}$ blotting. Quantification of densitometry analysis of protein expression levels. All data are presented as $\operatorname{means} \pm \mathrm{SEM}^{*} P<0.05,{ }^{* *} P<0.01$ significant difference compared with Sham group. ${ }^{\#} P<0.05$, ${ }^{\#} P<0.01$ significant difference compared with PHx group. 
Sham (6hrs)

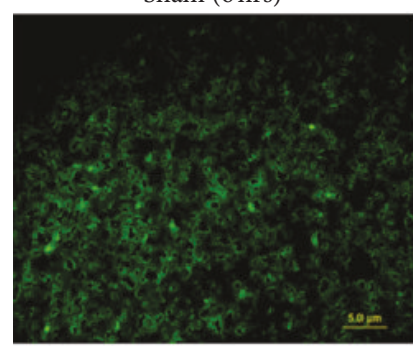

Sham (24hrs)

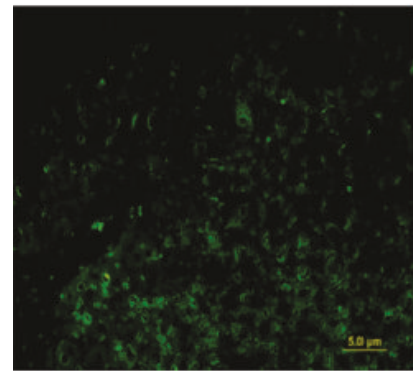

Sham (72 hrs)

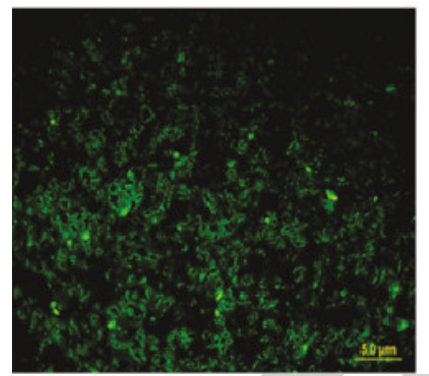

PHx (6hrs)

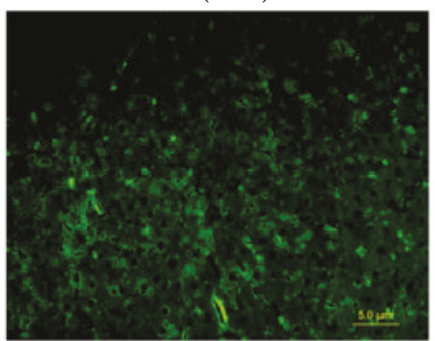

PHx (24hrs)

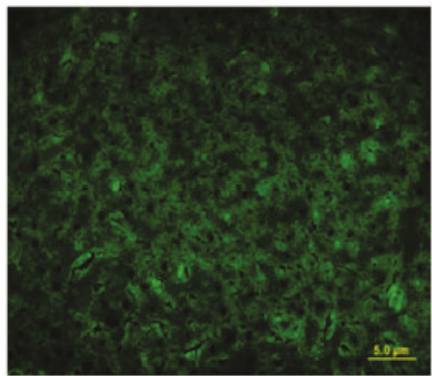

PHx (72 hrs)

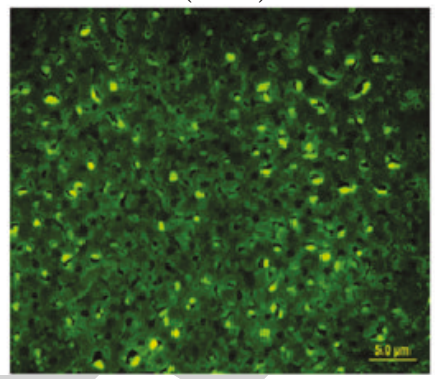

PHx (6hrs) + Sm

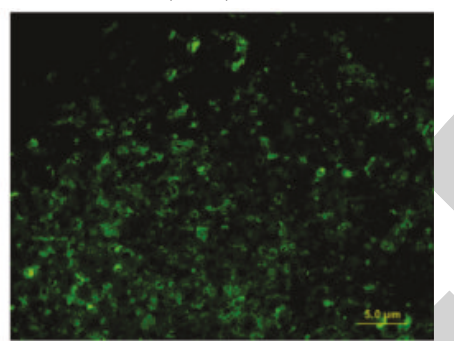

PHx (24hrs) + Sm

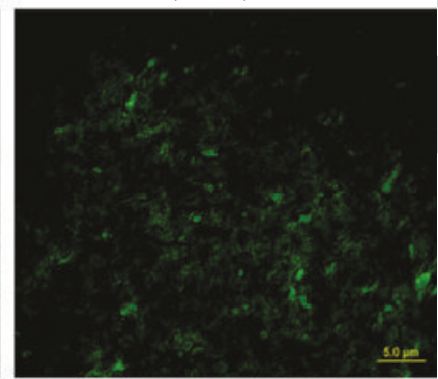

$\mathrm{PHx}$ (72hrs) $+\mathrm{Sm}$

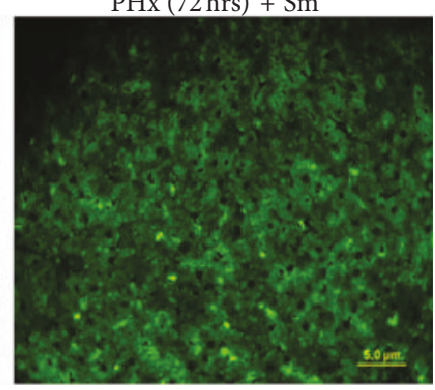

Figure 4: TUNEL assay in liver regeneration after PHx. To detect cell apoptosis during liver regeneration at different times. At 6 hrs PHx and $24 \mathrm{hrs}$ PHx was not found, but at $72 \mathrm{hrs}$ PHx appeared. Also not observed after silymarin treatment PHx $72 \mathrm{hrs}$.

3.3. Elephantopus scaber L. Accelerated Cell Cycle in Liver Regeneration. Cyclin D1/pRb and Cyclin E/E2F are key regulators of G1-to-S phase progression of the cell cycle. We found Cyclin D1 was increased at $24 \mathrm{hrs}$ and $72 \mathrm{hrs}$ PHx by ESL and Sm $\left({ }^{*} P<0.05,{ }^{* *} P<0.01\right.$ versusSham); however, $\mathrm{pRb}$ was only increased in Sm treatment (Figures 2(a) and 2(c)). The positive control, Silymarin, was permission increased at $6 \mathrm{hrs,}$ $24 \mathrm{hrs}$, and $72 \mathrm{hrs}$ PHx compared with Sham $\left({ }^{*} P<0.05\right.$, ${ }^{* *} P<0.01$ versus Sham) and PHx $\left({ }^{\#} P<0.05\right.$, ${ }^{\# \#} P<$ 0.01 versus PHx (Figure 3(b)). Moreover, Cyclin D1, Cyclin $\mathrm{E}, \mathrm{pRb}$, and E2F mRNA expression levels were increased at 72 hrs PHx by ESL or Sm treatment $\left({ }^{*} P<0.05,{ }^{* *} P<0.01\right.$ versus Sham). The same result we found $\mathrm{Sm}$ also increased compared with Sham and PHx (Figure 3(c)).

3.4. Effects of Elephantopus scaber L. on Cell Death after PHx. During liver regeneration after liver injury, hepatocytes were lost. Cell death or apoptosis was a physiological process to regulate hepatocyte development and maintain liver mass. We detected apoptosis protein bad and cytochrome $\mathrm{c}$ at $24 \mathrm{hrs}$ and $72 \mathrm{hrs}$ (Figures 5(a) and 5(b)). Apoptosis occurs rapid cellular divisions after $\mathrm{PHx}$, resulting in fine-tuning of the liver size and tissue remodeling. Therefore, the results showed us that Elephantopus scaber L. (ESL) and Silymarin $(\mathrm{Sm})$ induced bad and cytochrome $c$ protein and mRNA expression downregulated $\left({ }^{*} P<0.05,{ }^{* *} P<0.01\right.$ versus Sham). Moreover, TUNEL assay showed apoptotic body only at long time $72 \mathrm{hrs}$ PHx including Silymarin treatment (Figure 4). In contract, we also observed apoptotic body in traditional Chinese medicines. We did not find apoptotic body in ESL and Sm treatment at long time $72 \mathrm{hrs}$ PHx. We did not found any apoptotic body in treatment TCM at $24 \mathrm{hrs}$ PHx.

\section{Discussion}

The liver is one of the most complex organs, and the regeneration induced by surgical injury is an orchestrated response. In order to set in the optimal mass in relationship to its body size, the liver induced its compensatory hyperplasia mechanisms. Herbal medicines have been used to treat liver disorders for thousands of years in the East and have now become a promising therapy internationally for pathological liver conditions. Growth factors (HGF and IGF-I) and cytokine (TGF $\beta 1$ ) are triggering cell cycle progression from G0 phase to G1 phase. Hepatocyte growth factor, also known 


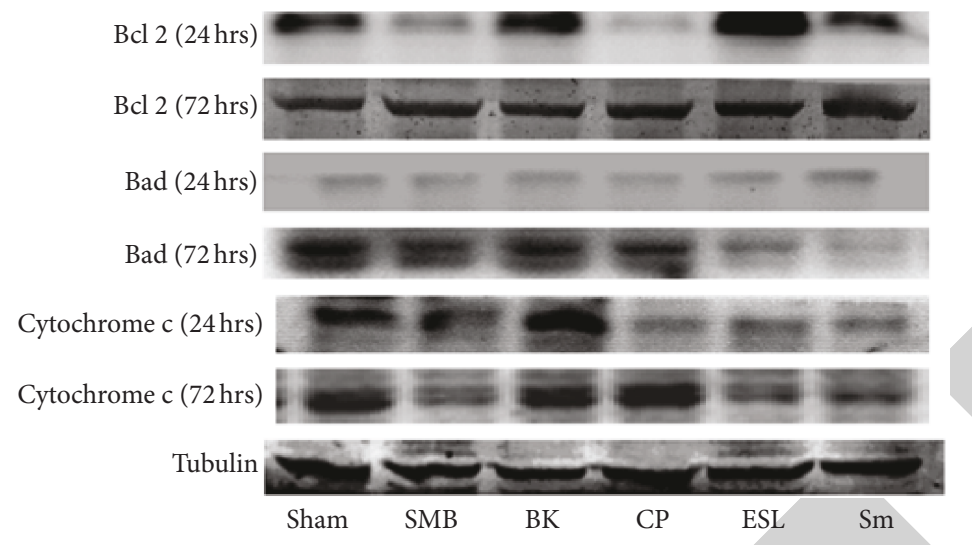

(a)
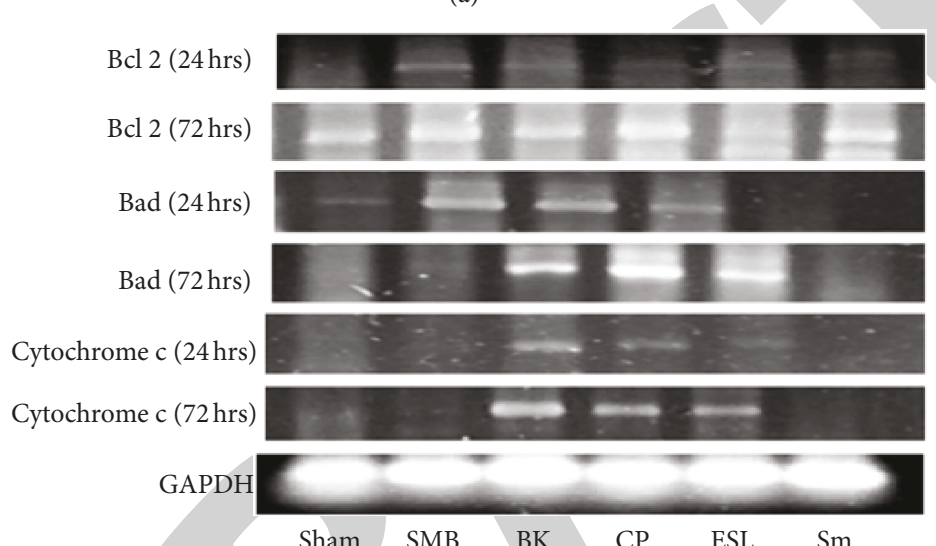

(b)
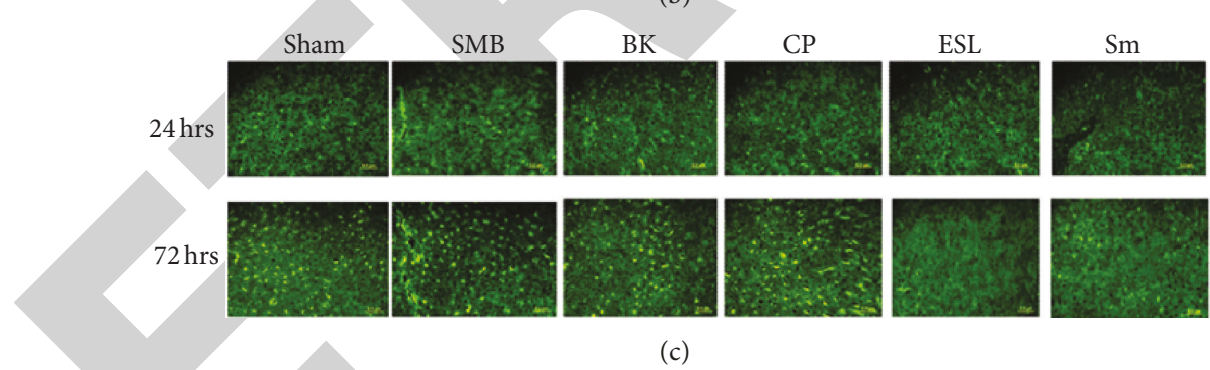

(c)

Figure 5: Elephantopus scaber L. suppressed apoptosis during liver regeneration. (a) Expression protein levels of Bad and cytochrome c were decreased protein expression in Elephantopus scaber L. (ESL) and Silymarin (Sm) after 24 hrs and 72 hrs PHx by western blot. However, antiapoptosis protein, Bcl 2, was increased by Elephantopus scaber L. (ESL) and Silymarin (Sm) at after $24 \mathrm{hrs}$ PHx, but no changes at $72 \mathrm{hrs}$ PHx. (b) mRNA expression levels of Bad and cytochrome c decreased apoptosis in ESL and Sm treatment at 24 hrs PHx; however, we can observed a little elevated expression at $72 \mathrm{hrs}$ PHx. In contrast, antiapoptosis protein, Bcl 2, was increased by Elephantopus scaber L. (ESL) and Silymarin (Sm) at $24 \mathrm{hrs}$, but no changes at $72 \mathrm{hrs}$. (c) TUNEL assay after traditional Chinese medicines in liver regeneration at $24 \mathrm{hrs}$ and $72 \mathrm{hrs}$ PHx. Only ESL and Sm have suppressed apoptosis function.

as scatter factor, is believed to play a primary role in liver regeneration. Growth factors may play a role in initiating the proliferation of hepatocytes after $\mathrm{PHx}$ in the rat were investigated immediately after surgical resection of the liver. In this paper, we presumed that Chinese medicines including Codonopsis pilosula (CP, Dangshen), Salvia miltiorrhiza Bunge (SMB, Tanshinone), Bupleurum Kasi (BK, Chaihu), Elephantopus scaber L. (ESL, Teng-Khia-U), and Silymarin $(\mathrm{Sm})$ may promote the function of liver regeneration after $\mathrm{PHx}$.
We found that ESL (Teng-Khia-U) and Silymarin (Sm) have the best effects on liver regeneration. In the present study, ESL from the toxicity study they were observed that the root extract are nontoxic and caused no death up to a dose of $3.2 \mathrm{~g} / \mathrm{kg}$ orally [24]. It is safe and was used in doses for the this study. Two known compounds, isodeoxyelephantopin and deoxyelephantopin [33, 34], were isolated from the whole plant of Elephantopus scaber L. (ESL, Teng-Khia-U) [35]. The whole plant of ESL is rich in novel antitumor substances-sesquiterpene lactones. The plant of 
ESL extracts has the ability to influence programmed cell death or arrest proliferation of tumor cells. We find that ESL and Sm stimulated several growth factors to regulate cell cycle and DNA synthesis. Growth factors are paracrineregulated hepatic regenerative response [36]. The active form of HGF is a powerful stimulator of DNA synthesis and cell motility $[37,38]$. PHx triggers the entry of rat liver cells into the cell cycle. We found ESL induced growth-regulated genes (HGF and IGF-I) to express later and persist longer, paralleling the rapid growth phase of the liver after $\mathrm{PHx}$ $[39,40]$. The maximal expression after 24 to $72 \mathrm{hrs}$ when the maximal growth period ends and are thought to be involved in re-establishing quiescence. Therefore, we can find that ESL mediated growth factors (HGF and IGF-I) and cytokines (TGF $\beta 1$ ) to remodel hepatic at $24 \mathrm{hrs} \mathrm{PHx}$, but fail to at $72 \mathrm{hrs}$ PHx. However, the other TCMs are also enhanced cytokines expression during this time [41-45]. Thus, $\mathrm{PHx}$ is a cell cycledependent regulation and a potential physiological role in G1 progression. Liver growth after PHx does not involve cell death and is a purely proliferative event. In summary, our data suggest liver regeneration may regulate the kinetics of cell cycle progression at the $\mathrm{G} 1$ to $S$ phase transition $[46,47]$. However, we found ESL induced growth factors and cell cycle expression at $24 \mathrm{hrs}$, until $72 \mathrm{hrs}$. Because ESL maybe delay apoptosis $[48,49]$.

Overall, the information thus derived should enhance our knowledge on the liver regeneration functions of treatment of TCMs as well as the basic mechanisms of cell cycle and apoptosis [50, 51].

\section{Abbreviations}

HGF: Hepatocyte growth factor

PHx: Partial hepatectomy

IGF-I: Insulin-like growth factor I

CP: Codonopsis pilosula

BK: Bupleurum kasi

ESL: Elephantopus scaber L.

SMB: Salvia miltiorrhiza Bunge

Sm: Silymarin

UPA: Urokinase plasminogen activator

TCMs: Traditional Chinese medicines.

\section{Authors' Contributions}

C.-C. Tsai and J.-P. Wu equally contributed to this work.

\section{Acknowledgments}

The authors who have taken part in this study declared that they do not have anything to disclose regarding funding or conflict of interests with respect to this paper. This study is supported in part by Taiwan Department of Health Clinical Trial and Research Center of Excellence (DOH101-TD-B111-004).

\section{References}

[1] R. Peng, Y. Wei, A. Wang, X. Wu, and L. Li, "Characteristics of element contents and their influence factors in Codonopsis tangshen," Zhongguo Zhongyao Zazhi, vol. 34, no. 11, pp. 1335-1338, 2009.

[2] H. T. Chen, Y. L. Tsai, Y. S. Chen et al., "Dangshen (Codonopsis pilosula) activates IGF-I and FGF-2 pathways to induce proliferation and migration effects in RSC96 schwann cells," American Journal of Chinese Medicine, vol. 38, no. 2, pp. 359-372, 2010.

[3] M. N. Li, W. B. Dong, M. Cao, C. L. Deng, and M. Y. Wang, "Role and mechanism of Salvia miltiorrhiza Bunge in alleviating injury induced by hypoxia/reoxygenation in HK-2 cells," Chinese Journal of Contemporary Pediatrics, vol. 9, no. 6, pp. 559-562, 2007.

[4] X. J. Wang, Z. B. Wang, and J. X. Xu, "Effect of salvianic acid $A$ on lipid peroxidation and membrane permeability in mitochondria," Journal of Ethnopharmacology, vol. 97, no. 3, pp. 441-445, 2005.

[5] C. C. Lin, M. H. Yen, J. Y. Chen et al., "Anatomical and histological studies of Bupleuri radix," The American Journal of Chinese Medicine, vol. 19, no. 3-4, pp. 265-274, 1991.

[6] G. Ji, "Clinical study on treatment of alcoholic liver disease by Qinggan Huoxue Recipe," Journal of Chinese Integrative Medicine, vol. 1, no. 2, pp. 103-124, 2003.

[7] C. C. Lin, C. C. Tsai, and M. H. Yen, "The evaluation of hepatoprotective effects of Taiwan folk medicine 'Teng-KhiaU', Journal of Ethnopharmacology, vol. 45, no. 2, pp. 113-123, 1995.

[8] N. Fausto and E. M. Webber, "Control of liver growth," Critical Reviews in Eukaryotic Gene Expression, vol. 3, no. 2, pp. 117-135, 1993.

[9] J. Kountouras, P. Boura, and N. J. Lygidakis, "Liver regeneration after hepatectomy," Hepato-Gastroenterology, vol. 48, no. 38, pp. 556-562, 2001.

[10] L. Braun, J. E. Mead, M. Panzica et al., “Transforming growth factor beta mRNA increases during liver regeneration: a possible paracrine mechanism of growth regulation," Proceedings of the National Academy of Sciences of the United States of America, vol. 85, no. 5, pp. 1539-1543, 1988.

[11] G. K. Michalopoulos and M. C. DeFrances, "Liver regeneration," Science, vol. 276, no. 5309, pp. 60-65, 1997.

[12] C. Surrenti, A. Casini, and S. Milani, "Is determination of serum N-terminal procollagen type III peptide (sPIIIP) a marker of hepatic fibrosis?" Digestive Diseases and Sciences, vol. 32, no. 7, pp. 705-709, 1987.

[13] H. Rosa, E. R. Parise, F. R. Paranhos et al., "Controlled production of cirrhosis in the rat liver," Arquivos de Gastroenterologia, vol. 28, no. 1, pp. 39-43, 1991.

[14] H. Nakatsukasa, R. P. Evarts, C. Hsia, and S. S. Thorgeirsson, "Transforming growth factor- $\alpha 1$ and type I procollagen transcripts during regeneration and early fibrosis of rat liver," Laboratory Investigation, vol. 63, no. 2, pp. 171-180, 1990.

[15] G. Eghbali-Fatourechi, G. C. Sieck, Y. S. Prakash, P. Maercklein, G. J. Gores, and L. A. Fitzpatrick, "Type I procollagen production and cell proliferation is mediated by transforming growth factor- $\beta$ in a model of hepatic fibrosis," Endocrinology, vol. 137, no. 5, pp. 1894-1903, 1996.

[16] G. Han, X. He, J. Yang et al., "Chemical constituents of Codonopsis pilosula Nannf," China Journal of Chinese Materia Medica, vol. 15, no. 2, pp. 105-127, 1990. 
[17] H. C. Wang, H. Zhang, and T. L. Zhou, "Protective effect of hydrophilic Salvia monomer on liver ischemia/reperfusion injury induced by pro-inflammatory cytokines," Chinese Journal of Integrated Traditional and Western Medicine, vol. 22, no. 3, pp. 207-210, 2002.

[18] R. T. Tian, P. S. Xie, and H. P. Liu, "Evaluation of traditional Chinese herbal medicine: Chaihu (Bupleuri Radix) by both high-performance liquid chromatographic and highperformance thin-layer chromatographic fingerprint and chemometric analysis," Journal of Chromatography A, vol. 1216, no. 11, pp. 2150-2155, 2009.

[19] H. L. Zhang, "Treatment of depression based on differentiation of the shaoyang channels," Journal of Traditional Chinese Medicine, vol. 30, no. 2, pp. 83-92, 2010.

[20] M. Su, H. Y. Chung, and Y. Li, "Deoxyelephantopin from Elephantopus scaber L. induces cell-cycle arrest and apoptosis in the human nasopharyngeal cancer CNE cells," Biochemical and Biophysical Research Communications, vol. 411, no. 2, pp. 342-347, 2011.

[21] D. Wakana, N. Kawahara, and Y. Goda, "Three new triterpenyl esters, codonopilates A-C, isolated from Codonopsis pilosula," Journal of Natural Medicines, vol. 65, no. 1, pp. 18-23, 2011.

[22] Y. Zhang, R. X. Wei, X. B. Zhu et al., "anshinone IIA induces apoptosis and inhibits the proliferation, migration, and invasion of the osteosarcoma MG-63 cell line in vitro," Anti-Cancer Drugs, vol. 23, no. 2, pp. 212-219, 2012.

[23] M. H. Yen, T. C. Weng, S. Y. Liu, C. Y. Chai, and C. C. Lin, "The hepatoprotective effect of Bupleurum kaoi, an endemic plant to Taiwan, against dimethylnitrosamine-induced hepatic fibrosis in rats," Biological and Pharmaceutical Bulletin, vol. 28, no. 3, pp. 442-448, 2005.

[24] L. Duan, S. N. Wallace, A. Engelberth et al., "Extraction of coproducts from biomass: example of thermal degradation of silymarin compounds in subcritical water," Applied Biochemistry and Biotechnology, vol. 158, no. 2, pp. 362-373, 2009.

[25] D. Y. Park and K. S. Suh, "Transforming growth factor$\beta 1$ protein, proliferation and apoptosis of oval cells in acetylaminofluorene-Induced rat liver regeneration," Journal of Korean Medical Science, vol. 14, no. 5, pp. 531-538, 1999.

[26] A. T. Weiss, N. M. Delcour, A. Meyer et al., "Efficient and costeffective extraction of genomic DNA from formalin-fixed and paraffin-embedded tissues," Veterinary Pathology, vol. 48, no. 4, pp. 834-838, 2011.

[27] Y. Gavrieli, Y. Sherman, and S. A. Ben-Sasson, "Identification of programmed cell death in situ via specific labeling of nuclear DNA fragmentation," The Journal of Cell Biology, vol. 119, no. 3, pp. 493-501, 1992.

[28] H. Billig, I. Furuta, and A. J. Hsueh, "Estrogens inhibit and androgens enhance ovarian granulosa cell apoptosis," Endocrinology, vol. 133, no. 5, pp. 2204-2212, 1993.

[29] F. Rohwer and F. Azam, "Detection of DNA damage in prokaryotes by terminal deoxyribonucleotide transferase-mediated dUTP nick end labeling," Applied and Environmental Microbiology, vol. 66, no. 3, pp. 1001-1006, 2000.

[30] H. Towbin, T. Staehelin, and J. Gordon, "Electrophoretic transfer of proteins from polyacrylamide gels to nitrocellulose sheets: procedure and some applications," Proceedings of the National Academy of Sciences of the United States of America, vol. 76, no. 9, pp. 4350-4354, 1979.

[31] T. D. Schmittgen, B. A. Zakrajsek, A. G. Mills et al., "Quantitative reverse transcription-polymerase chain reaction to study
mRNA decay: comparison of endpoint and real-time methods," Analytical Biochemistry, vol. 285, no. 2, pp. 194-204, 2000.

[32] N. Mahapoonyanont, T. Mahapoonyanont, N. Pengkaew, and R. Kamhangkit, "Power of the test of one-way ANOVA after transforming with large sample size data," in Proceedings of the 1st World Conference on Learning, Teaching and Administration (WCLTA '10), vol. 9, pp. 933-937, October 2010.

[33] I. H. L. Hamelers, R. F. M. A. Van Schaik, J. Sipkema, J. S. Sussenbach, and P. H. Steenbergh, "Insulin-like growth factor I triggers nuclear accumulation of cyclin D1 in MCF-7S breast cancer cells," The Journal of Biological Chemistry, vol. 277, no. 49, pp. 47645-47652, 2002.

[34] N. Fausto and E. M. Webber, "Mechanisms of growth regulation in liver regeneration and hepatic carcinogenesis," Progress in liver diseases, vol. 11, pp. 115-137, 1993.

[35] S. N. Wallace, D. J. Carrier, and E. C. Clausen, "Batch solvent extraction of flavanolignans from milk thistle (Silybum marianum L. Gaertner)," Phytochemical Analysis, vol. 16, no. 1, pp. 7-16, 2005.

[36] H. J. Kwon, Y. S. Won, Y. D. Yoon et al., "Vitamin D3 upregulated protein 1 deficiency accelerates liver regeneration after partial hepatectomy in mice," Journal of Hepatology, vol. 54, no. 6, pp. 1168-1176, 2011.

[37] H. R. Reiske, J. Zhao, D. C. Han, L. A. Cooper, and J. L. Guan, "Analysis of FAK-associated signaling pathways in the regulation of cell cycle progression," FEBS Letters, vol. 486, no. 3, pp. 275-280, 2000.

[38] G. Michalopoulos, "HGF and liver regeneration," Gastroenterologia Japonica, vol. 28, pp. 36-39, 1993.

[39] R. Zarnegar, M. C. DeFrances, D. P. Kost, P. Lindroos, and G. K. Michalopoulos, "Expression of hepatocyte growth factor mRNA in regenerating rat liver after partial hepatectomy," Biochemical and Biophysical Research Communications, vol. 177, no. 1, pp. 559-565, 1991.

[40] S. Skrtic, K. Wallenius, O. G. lsaksson et al., "Possible roles of insulin-like growth factor in regulation of physiological and pathophysiological liver growth," Hormone Research, vol. 55, pp. 1-6, 2001.

[41] M. L. Liu, W. M. Mars, R. Zarnegar, and G. K. Michalopoulos, "Collagenase pretreatment and the mitogenic effects of hepatocyte growth factor and transforming growth factor- $\alpha$ in adult rat liver," Hepatology, vol. 19, no. 6, pp. 1521-1527, 1994.

[42] L. Wang, S. Jian, P. Nan, and Y. Zhong, "Chemical composition of the essential oil of Elephantopus scaber from Southern China," Zeitschrift fur Naturforschung C, vol. 59, no. 5-6, pp. 327-329, 2004.

[43] E. S. Ong, "Extraction methods and chemical standardization of botanicals and herbal preparations," Journal of Chromatography $B$, vol. 812, no. 1-2, pp. 23-33, 2004.

[44] K. Matsumoto and T. Nakamura, "Hepatocyte growth factor: molecular structure and implications for a central role in liver regeneration," Journal of Gastroenterology and Hepatology, vol. 6, no. 5, pp. 509-519, 1991.

[45] C. D. Zois, G. H. Baltayiannis, P. Karayiannis, and E. V. Tsianos, "Systematic review: hepatic fibrosis-regression with therapy," Alimentary Pharmacology and Therapeutics, vol. 28, no. 10, pp. 1175-1187, 2008.

[46] M. P. Crippa, "Urokinase-type plasminogen activator," The International Journal of Biochemistry \& Cell Biology, vol. 39, no. 4, pp. 690-694, 2007. 
[47] C. C. Huang, C. P. Lo, C. Y. Chiu, and L. F. Shyur, "Deoxyelephantopin, a novel multifunctional agent, suppresses mammary tumour growth and lung metastasis and doubles survival time in mice," British Journal of Pharmacology, vol. 159, no. 4, pp. 856-871, 2010.

[48] J. O. McGee and A. Fallon, "Hepatic cirrhosis-a collagen formative disease?" Journal of Clinical Pathology, vol. 12, pp. 150-157, 1978.

[49] G. Xu, Q. Liang, Z. Gong, W. Yu, S. He, and L. Xi, "Antitumor activities of the four sesquiterpene lactones from Elephantopus scaber L.," Experimental Oncology, vol. 28, no. 2, pp. 106-109, 2006.

[50] J. A. Ehrenfried, T. C. Ko, E. A. Thompson, and B. M. Evers, "Cell cycle-mediated regulation of hepatic regeneration," Surgery, vol. 122, no. 5, pp. 927-935, 1997.

[51] E. M. Webber, M. J. FitzGerald, P. I. Brown, M. H. Bartlett, and N. Fausto, "Transforming growth factor- $\alpha$ expression during liver regeneration after partial hepatectomy and toxic injury, and potential interactions between transforming growth factor$\alpha$ and hepatocyte growth factor," Hepatology, vol. 18, no. 6, pp. 1422-1431, 1993.

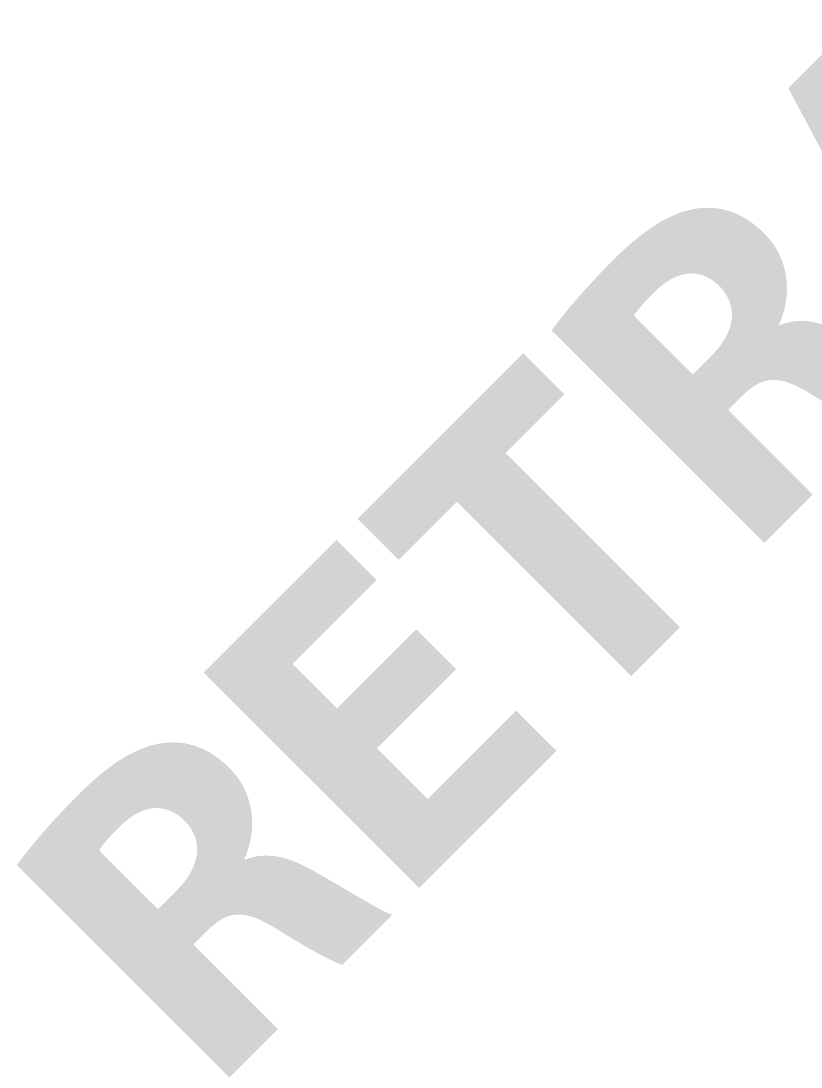

